\title{
Definitive Clinical Assessment of Atrial Septal Defect by Magnetic Resonance Imaging
}

\author{
A. M. Taylor, ${ }^{1}$ R. H. Stables,, ${ }^{2}$ P. A. Poole-Wilson, ${ }^{2}$ \\ and D. J. Pennell' \\ 'Magnetic Resonance Unit, Royal Brompton Hospital, London, UK \\ ${ }^{2}$ Department of Cardiology, Royal Brompton Hospital, London, UK
}

\section{INTRODUCTION}

In patients with a pulmonary-to-systemic shunt ratio (Qp/Qs) of 2 or greater there is increasing evidence that atrial septal defect (ASD) closure can improve long-term survival, irrespective of age (1). ASD closure can be performed surgically or by use of percutaneous transcatheter devices. For transcatheter device placement, the ASD must be centrally placed and have a diameter of less than $2.5 \mathrm{~cm}$, with an adequate rim of atrial septum for device attachment (2). A full noninvasive assessment of ASD by conventional imaging can prove difficult, and invasive approaches also produce significant errors (3). In this report we describe how magnetic resonance imaging (MRI) was able to comprehensively define both the anatomic and functional significance of an ASD and allow informed clinical management in a patient in whom conventional invasive and noninvasive investigations had proved inconclusive.

\section{CASE REPORT}

After a routine medical examination, a 25-yr-old asymptomatic woman was referred for investigation of a systolic murmur. She had been fully active with appar- ently normal exercise tolerance throughout her life. Clinical findings were consistent with a moderate left-to-right shunt through an ASD, with a left parasternal heave, fixed splitting of the second heart sound, and a $3 / 6$ ejection systolic murmur in the pulmonary area.

An electrocardiogram revealed sinus rhythm with right axis deviation and incomplete right bundle branch block. Chest x-ray demonstrated mild pulmonary plethora. Transthoracic echocardiogram revealed a moderatesized secundum ASD and a dilated right ventricle. At cardiac catheterization, left ventricular function and coronary anatomy were normal, the pulmonary artery pressure was $18 / 9$ (mean 14), and there was a left-to-right shunt at the level of the atria with a Qp/Qs of 1.7 estimated by oximetry. The patient was diagnosed as having a secundum ASD with a moderate left-to-right shunt and was managed conservatively with yearly follow-up.

At review $3 \mathrm{yr}$ after presentation, the patient remained asymptomatic with no change on examination. However, transthoracic echocardiogram suggested worsening of the left-to-right shunt through the ASD, with a hyperdynamic right ventricle and a dilated pulmonary artery (peak velocity $1.2 \mathrm{~m} / \mathrm{sec}$ ). Review of the previous catheter data showed that the superior vena cava oxygen saturation had

Received March 10, 1998; Accepted May 13, 1998

Address reprint requests to A. M. Taylor. 
a)

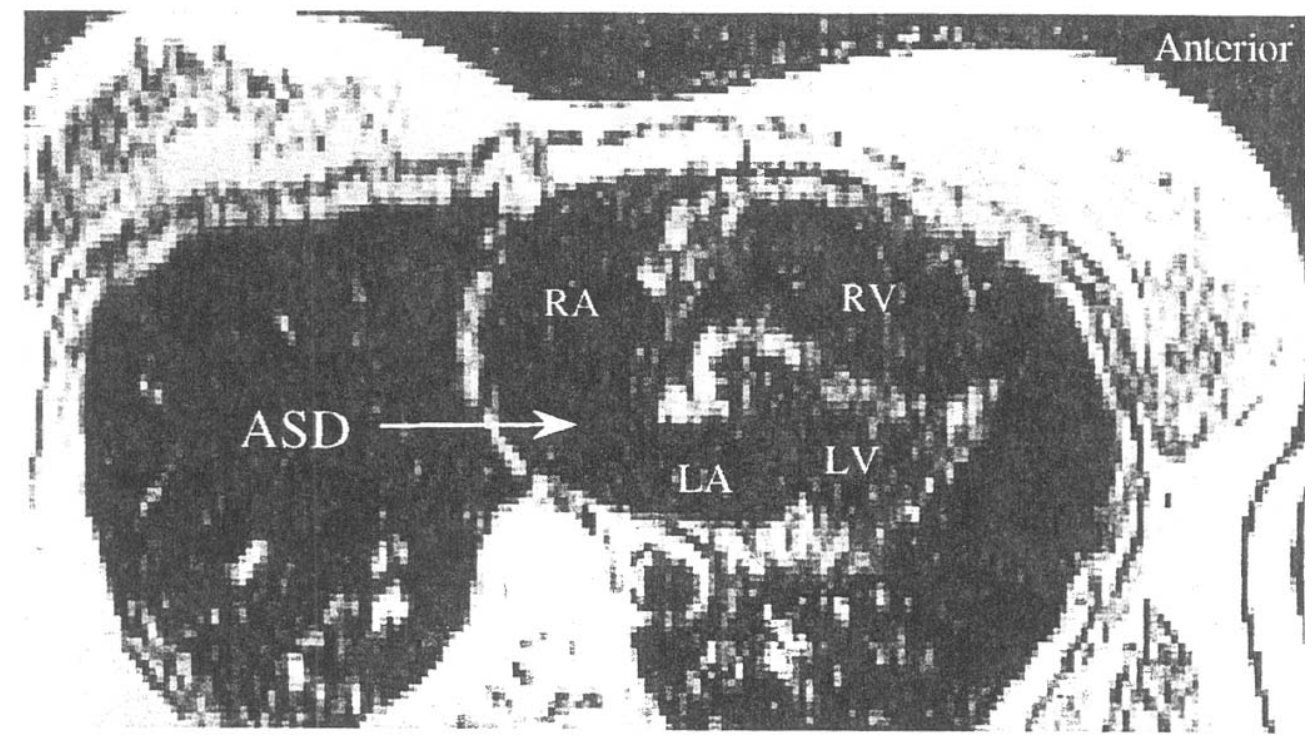

b)

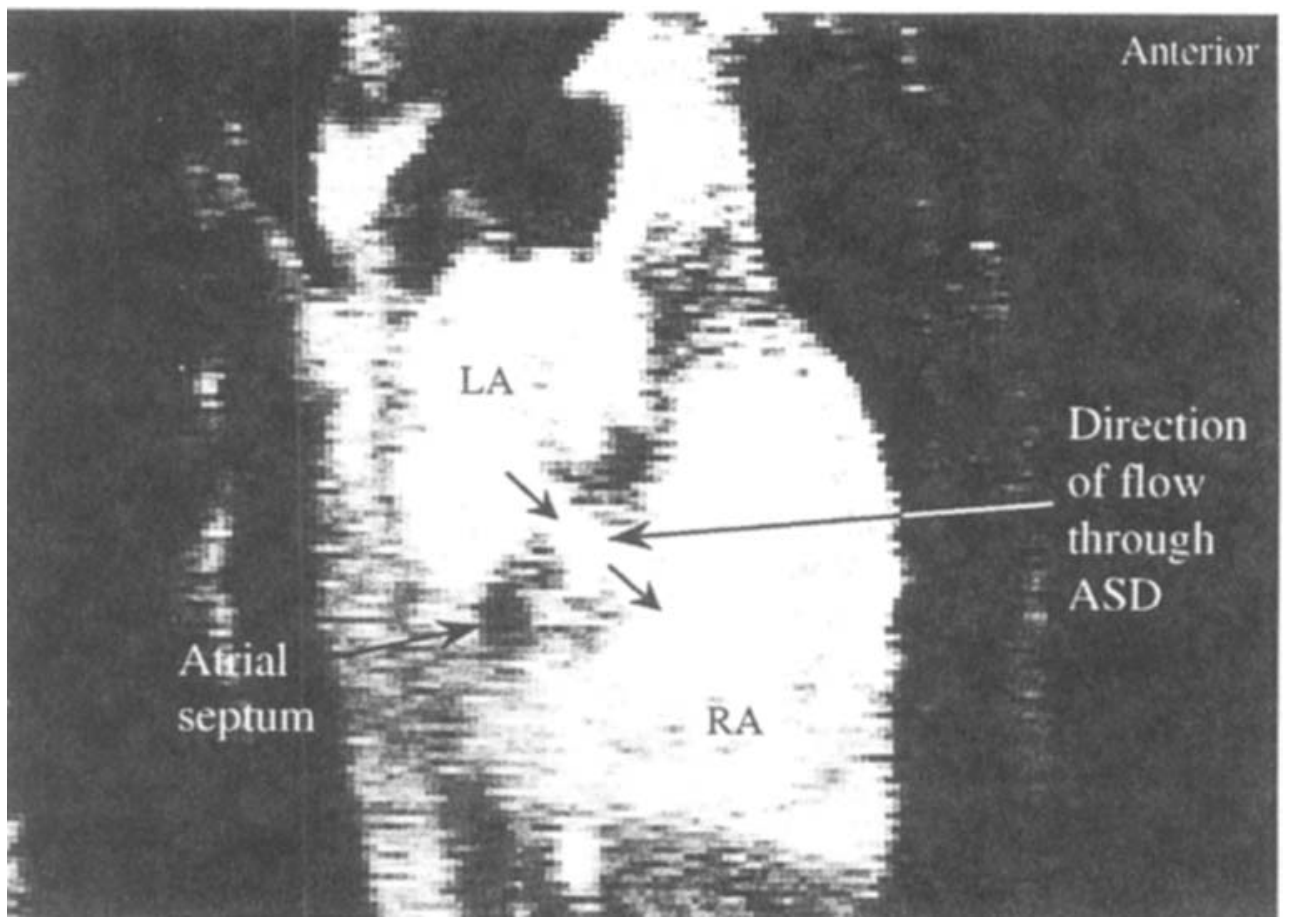

Figure 1. MRI of ASD. (a) Spin-echo image in the transaxial plane revealing large ASD, dilated right atrium (RA), dilated right ventricle (RV), and fattened ventricular septum. LA, left atrium; LV, left ventricle. (b) Gradient-echo image in oblique sagittal plane; arrow indicates direction of flow across ASD. 
been elevated at $93.5 \%$, and doubt was cast over the validity of the calculated $\mathrm{Qp} / \mathrm{Qs}$ from the initial catheter study. Although the most recent echocardiogram was compatible with a large defect, accurate evaluation of the $\mathrm{Qp} / \mathrm{Qs}$ was difficult (3), and it was not possible to assess the suitability for a closure device. The patient did not wish to undergo a further invasive procedure, and therefore an MRI was requested to establish the degree of leftto-right shunting, the size and position of the ASD, and to exclude anomalous pulmonary venous drainage.

\section{Magnetic Resonance Imaging}

Spin-echo images acquired in the transaxial plane confirmed the presence of an ASD. There was dilatation of the right atrium and ventricle, with flattening of the ventricular septum consistent with right ventricular overload [Fig. 1(a)]. The main pulmonary trunk was also dilated $(3.4 \times 3.6 \mathrm{~cm})$. There was no evidence of anomalous pulmonary venous drainage.
Gradient-echo images were used to align the atrial septum in plane [Fig. 1(b)], because spin-echo imaging may overestimate ASD size $(4,5)$. The atrial septum was then viewed from within the right atrium using phase velocity mapping (Fig. 2). A large ASD was seen in these images with an area of $5.6 \mathrm{~cm}^{2}$ and a maximum diameter of $3.5 \mathrm{~cm}$. Two fenestrations were seen peripheral to the main ASD orifice (areas 0.25 and $0.3 \mathrm{~cm}^{2}$, respectively). The ASD was also noted to be asymmetrically positioned toward the valvular ring, with very little tissue with which to consider transcatheter device closure.

Further phase velocity maps were acquired in the aorta and main pulmonary trunk, and the systemic and pulmonary flows were measured $(3.1$ and $13.21 / \mathrm{min}$, respectively; Fig. 3). A Qp/Qs of $4.3 \pm 0.4$ was calculated.

On the basis of the MRI study, conservative medical management was not considered appropriate. Percutaneous transcatheter device closure was also not considered an option, because MRI had demonstrated an asymmetrically positioned ASD orifice, with an area of $>2.5 \mathrm{~cm}^{2}$,

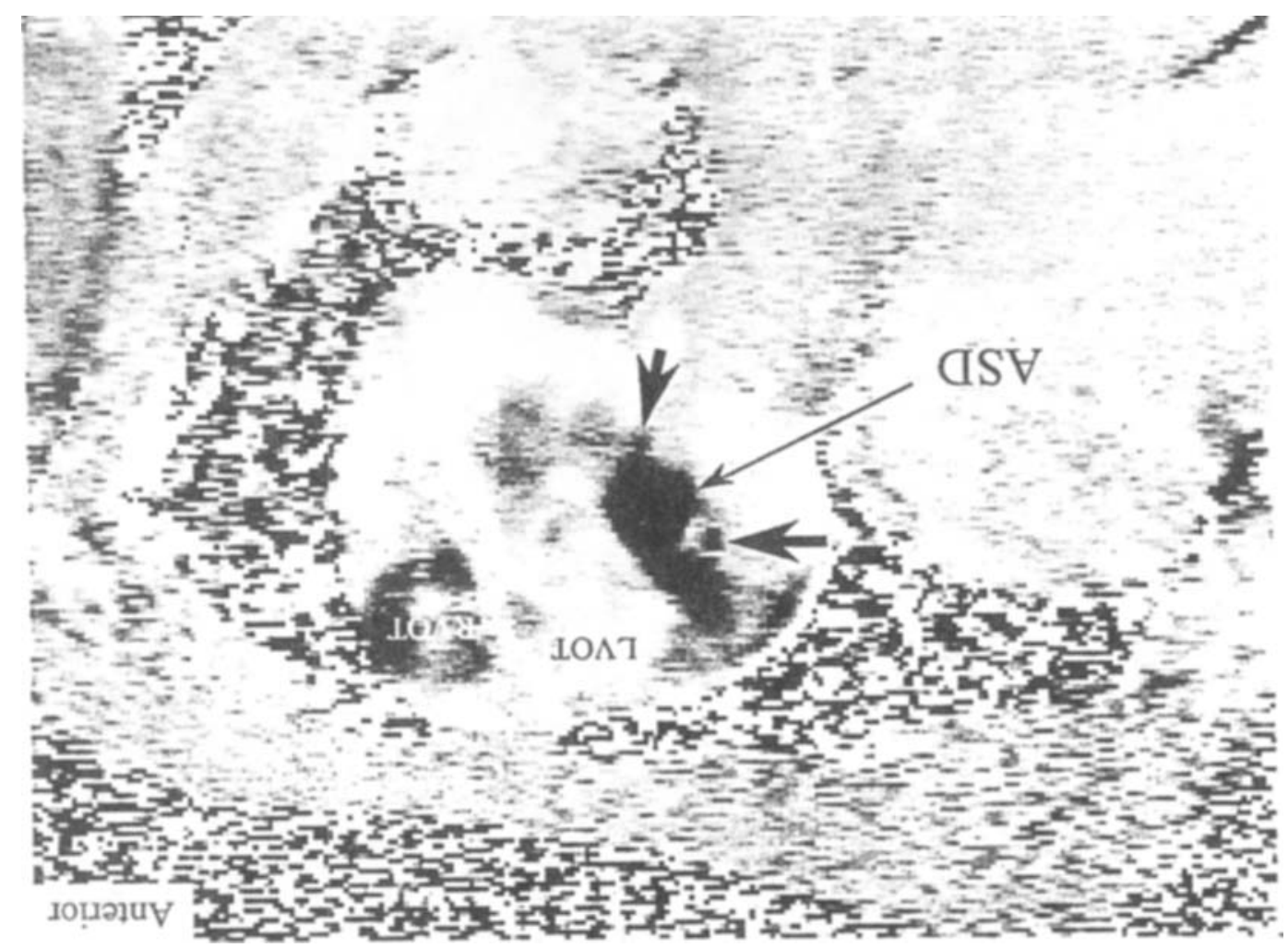

Figure 2. Phase velocity map viewed from the right atrium in an oblique transaxial plane. RVOT, right ventricular outflow tract; LVOT, left ventricular outflow tract. Large ASD seen with a maximum diameter of $3.5 \mathrm{~cm}$ and an area of $5.6 \mathrm{~cm}^{2}$. Thick arrows indicate fenestrations. Black pixels in the region of the atrial septum represent flow across the ASD into the right atrium. 
a)

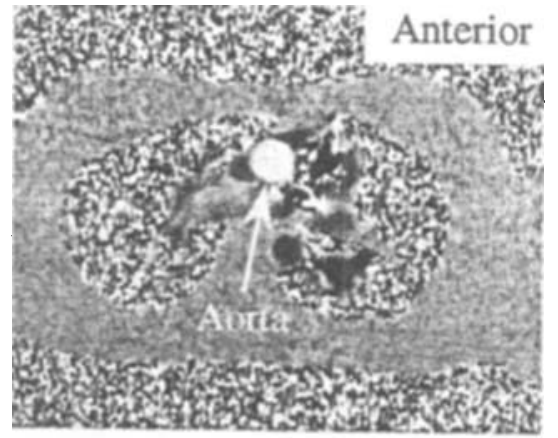

b)

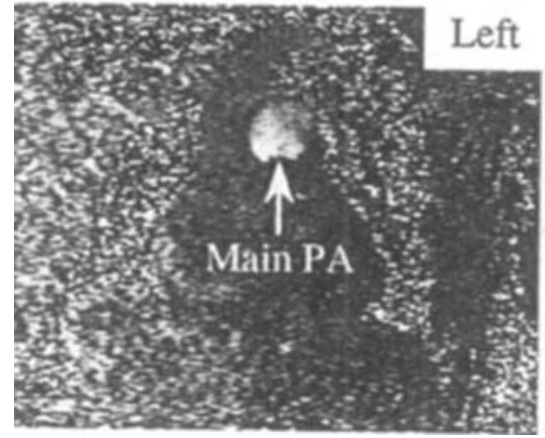

c)

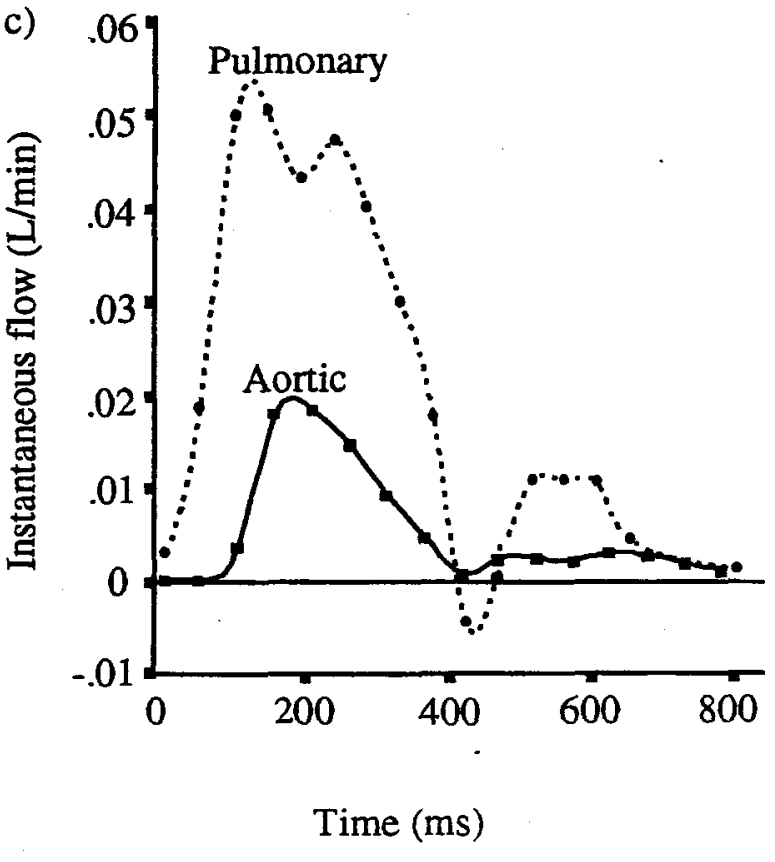

Figure 3. Measurement of systemic and pulmonary flow. (a) Velocity map (single frame) in a transverse plane for measurement of flow in the aorta. (b) Velocity map (single frame) in a coronal plane for measurement of flow in the main pulmonary trunk (Main PA). (c) Instantaneous systemic (-) and pulmonary (- -) flow plotted against time for a single RR interval. The flow is calculated from the area under each curve, $Q p / Q_{s}-4.3 / 1$.

peripheral fenestrations, and too little tissue adjacent to the atrioventricular ring for device attachment. The patient was therefore referred for surgical closure of the ASD.

\section{Operative Findings}

A large secundum ASD measuring approximately 3.5 $\times 2.5 \mathrm{~cm}$ was found. There were several small fenestrations around the main septal defect orifice. The entire region was excised. The remaining defect was closed with autologous pericardium and continuous sutures.

\section{DISCUSSION}

Oximetry at the time of cardiac catheterization is widely used in the assessment of ASDs. This case highlights the limitation of this technique, because small errors in the measurement of right-sided oxygen content or saturation can lead to sizeable changes in the calculated pulmonary flow (3). The aberrant superior vena cava oxygen saturation measured in this patient's initial catheter may have been sampled within the left atrium and probably led to miscalculation of the $\mathrm{Qp} / \mathrm{Qs}$. In addition, it proved difficult to estimate the shunt size and ASD location with conventional echocardiography, limiting management decisions. MRI offers an ideal noninvasive method for assessing intracardiac shunts. Anatomic size, position, and the presence of fenestrations can all be visualized, whereas at a functional level both the pulmonary and systemic flow can be measured to yield all the information needed for clinical management.

There is good agreement between MRI and oximetric and indicator dilution catheter techniques for the calculation of pulmonary-to-systemic shunting in ASDs under ideal conditions $(6,7)$. Similarly, good agreement has been demonstrated between the ASD size estimated by MRI and balloon sizing at catheterization or template sizing at operation (5). These latter results are comparable with the best results reported for ASD sizing by transthoracic (8) and transesophageal (9) echocardiography, al- 
though MRI has the advantage of being able to visualize the ASD en face and can thus define shape and dimension.

In conclusion, we demonstrated that MRI can provide conclusive diagnostic and management information in ASD. MRI should be used if accurate visualization of the atrial septum and measurement of the $Q p / Q s$ are required or where conventional techniques are impractical or have given inconclusive information.

\section{ACKNOWLEDGMENTS}

Andrew Taylor is funded by the Coronary Artery Disease Research Association. We thank Philip Kilner for his help with the magnetic resonance imaging.

\section{REFERENCES}

1. Konstantinides S, Geibel A, Olschewski M, Görnandt L, Roskamm H, Spillner G, Just H and Kasper W. A comparison of surgical and medical therapy for atrial septal defect in adults. $N$ Engl $J$ Med, 1995; 333:469-473.

2. Lloyd TR, Rao PS, Beekman RH, Mendelsohn AM and Sideris EB. Atrial septal defect occlusion with the buttoned device (a multi-institutional U.S. trial). Am J Cardiol, 1994; 73:286-291.

3. Boehrer JD, Lange RA, Willard JE, Grayburn PA and Hillis LD. Advantages and limitations of methods to detect, localise and quantitate intracardiac left-to-right shunting. Am Heart J, 1992; 124:448-455.

4. Diethelm L, Déry R, Lipton MJ and Higgins CB. Atriallevel shunts: Sensitivity and specificity of MR in diagnosis. Radiology, 1987; 162:181-186.

5. Holmvang G, Palacios IF, Vlahakes GJ, Dinsmore RE, Miller SW, Liberthson RR, Block PC, Ballen B, Brady TJ and Kantor HL. Imaging and sizing of atrial septal defects by magnetic resonance imaging. Circulation, 1995; 92: 3473-3480.

6. Brenner LD, Caputo GR, Mostbeck G, Steinman D, Dulce M, Cheitlin MD, O'Sullivan M and Higgins CB. Quantification of left to right atrial shunts with velocity-encoded cine nuclear magnetic resonance imaging. J Am Coll Cardiol, 1992; 20:1246-1250.

7. Hundley WG, Li HF, Lange RA, Pfeifer DP, Meshack BM, Willard JE, Landau C, Willett D, Hillis LD and Reshock R. M. Assessment of left-to-right intracardiac shunting by velocity-encoded, phase-difference magnetic resonance imaging: A comparison with oximetric and indicator dilution techniques. Circulation, 1995; 91:2955-2960.

8. Rao PS, Langhough R, Beekman RH, Lloyd TR and Sideris EB. Echocardiographic estimation of balloonstretched diameter of secundum atrial septal defect for transcatheter occlusion. Am Heart J, 1992; 124:172175.

9. Faletra F, Scarpini S, Moreo A, Ciliberto GR, Austoni P, Donatelli $F$ and Gordini V. Color Doppler echocardiographic assessment of atrial septal defect size: correlation with surgical measurements. J Am Soc Echocardiogr, 1991; 4:429-434. 